\title{
Multiple system atrophy: the nature of the beast revisited
}

\author{
Niall Quinn
}

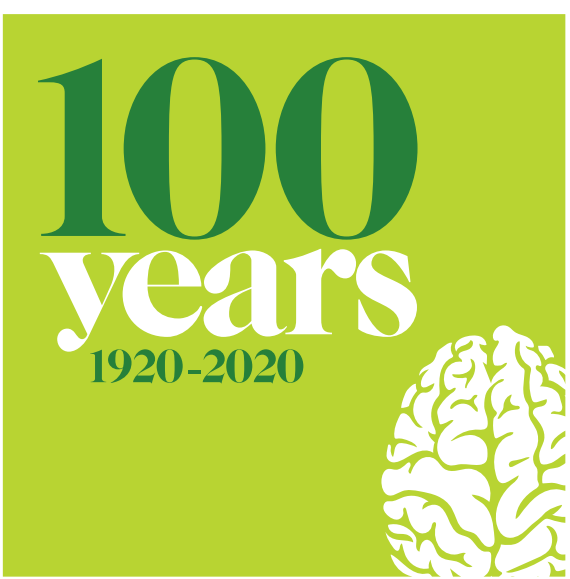

It is now 50 years since Graham and Oppenheimer first coined the term multiple system atrophy (MSA). ${ }^{1}$ Twenty years later, I wrote an extensive review of MSA entitled 'The nature of the beast'.' This alluded to blindfolded men examining an elephant from different directions and coming away with different perceptions (figure 1). Not long ago, a propos of MSA, my uroneurologist friend Clare Fowler (personal communication), commented, "You know, it all makes sense now, but 30 years ago that was far from being the case."

I got hooked on neurology, and on movement disorders in particular, in my first neurology post as SHO to David Marsden at King's College Hospital. Later, I worked for Roger Bannister at Queen Square, where I encountered a number of severely affected inpatients with MSA.

I read the papers of Dejerine and Thomas $^{3}$ on sporadic olivopontocerebellar degeneration (sOPCA, now MSAC), Bradbury and Eggleston ${ }^{4}$ on postural hypotension, Shy and Drager (1960) on their syndrome (Shy-Drager ${ }^{5}$ syndrome; SDS), and of Adams et $a l^{6}$ on striatonigral degeneration (SND now MSA-P). Other key developments in the busy 1960s (which I still think of as the decade of the basal ganglia) were the introduction of levodopa in 1967, Hoehn and Yahr's landmark (pre-levodopa) 1967 paper $^{7}$ on a large cohort with Parkinson's disease and parkinsonism, Steele et al's description of

Correspondence to Professor Niall Quinn, UCL Institute of Neurology, London WC1N 3BG, UK; niallquinn@blueyonder.co.uk their syndrome, ${ }^{8}$ later called progressive supranuclear palsy (PSP) and Rebeiz et al's paper on corticodentatonigral degeneration, now called corticobasal degeneration (CBD). ${ }^{9}$

Later, in 1972, Bannister and Oppenheimer had described in Brain ${ }^{10} 16$ pathologically confirmed cases of neurogenic autonomic failure, 11 of whom had MSA, 3 of whom had Parkinson's disease (PD) and 2 of whom had pure autonomic failure with Lewy body pathology.

On returning to King's in 1980 as a research fellow, three things gave me the opportunity to make sense of the atypical parkinsonian disorders, particularly MSA. First, I saw many parkinsonian patients every single week, learning what was 'typical' to better recognise the atypical; second, I remained there for 8 years, following up all my patients long term; third, many patients, especially atypical ones, came to autopsy, the ultimate diagnostic quality control, in the Parkinson's Disease Society Brain Bank.

Despite the landmark papers above, in the 1980s, there was still widespread confusion about atypical parkinsonism. In particular, there were no widely applied diagnostic criteria, rating scales or prevalence figures for MSA, PSP or CBD. The abbreviation PAF was used both for cases of MSA with progressive autonomic failure, but also for pure autonomic failure without other neurology, and there was little realisation that cardiovascular autonomic failure was very common in PD as well as in MSA. As a result, the term SDS, the pathology of which was MSA, was frequently misapplied to cases with PD and autonomic failure. Both hereditary and sporadic cerebellar degenerations were often lumped together as OPCA, and no-one knew whether to lump or split SDS, SND and OPCA. MSA became blurred with other multisystem degenerations (figure 2). Even Oppenheimer revealed that he was not certain where MSA began and where it ended: "I chose multiple system atrophy-probably unwisely, as this term would seem to be applicable to other conditions such as Friedreich's ataxia. What I did not do was to define the limits of applicability of the

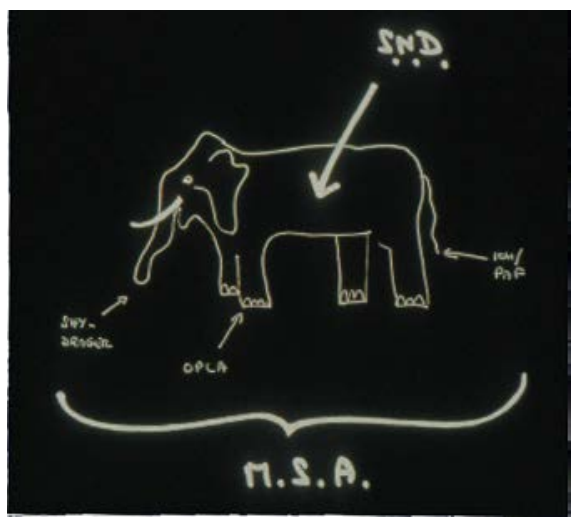

Figure 1 The MSA Elephant.

term MSA. I could not even reach a firm opinion on whether all cases of OPCAwith or without autonomic failure-were suffering from one and the same disease."

I set about studying cases with atypical parkinsonism and trying to dissect, beyond the presence of autonomic failure plus parkinsonism or cerebellar features, other features of MSA that helped to identify a discrete entity, and to come up with some diagnostic criteria. A thorough review of the literature revealed that 'hereditary OPCA' (later to spawn dozens of SCAs) differed from sOPCA in terms of age at onset and prognosis. 'SND' cases with predominant parkinsonism were also sporadic. They usually had a poor or suboptimal response to levodopa, and rarely developed significant dementia. Moreover, no pathologically proven case of 'SND' or 'sOPCA' with onset before age 30 had been reported, and onset before age 40 was very uncommon.

The most common cause for diagnostic confusion with MSA was, and still is, Lewy body disease, especially cases with dementia and autonomic failure manifesting as PD dementia (PDD) or dementia with Lewy bodies (DLB), and the next most common was PSP. The UKPD Society Brain Bank criteria for PD were published in 1988, diffuse Lewy body disease (a pathological construct) in 1989, and DLB and PDD in 1996. The time was ripe for some clarity on MSA.

In 1988, the JNNP invited me to write a contribution, on a topic of my choice, 


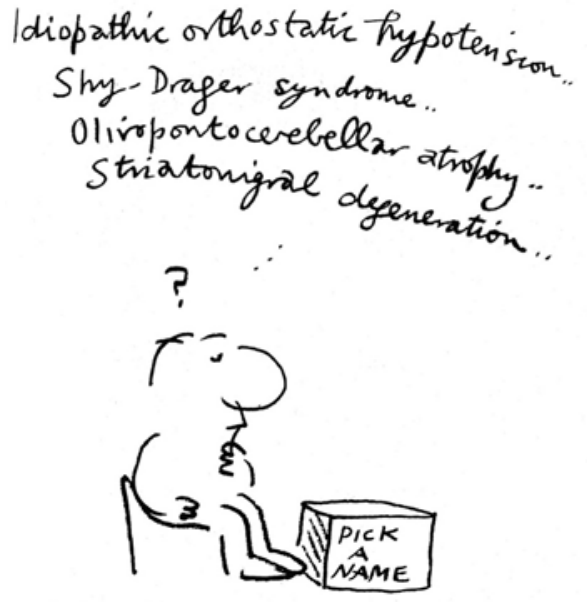

Figure 2 To lump or not to lump?

for a special supplement to mark the end of David Marsden's 10-year stint as editor, and I seized the opportunity to put together my thoughts on MSA.

My observations and researches enabled me to come up with the first proper set of diagnostic criteria for MSA, with levels of possible, probable and definite (pathologically proven) certainty, mirroring schemata for other diseases. These criteria have fairly well stood the test of time, with modifications in 1998 and 2008, ${ }^{11}$ and now plans for further revision.

In addition to the 'core' structural diagnostic features, I also raised awareness of a number of 'red flags' favouring MSA, including poor levodopa response, emotional incontinence, early instability and falls, rapid progression, pyramidal signs, irregular jerky tremor or (polymini) myoclonus, severe dysarthria or dysphonia (particularly a characteristic high-pitched strained quivery or slurring speech), stridor, dysphagia, disproportionate antecollis, atypical dystonic levodopa-induced dyskinesias, contractures and Raynaud's phenomenon. Other red flags added later were inspiratory sighs, new excessive snoring, and cold and dusky extremities. Some of these features, for example, early instability and falls, dysarthria and dysphagia, were also common to PSP, but the presence of a supranuclear gaze palsy and the absence of autonomic failure set it apart from MSA and PD.

As I was writing my clinical JNNP paper, unknown to me the neuropathologists Papp, Kahn and Lantos were putting the final touches to their Brain paper, ${ }^{12}$ also published in 1989, describing oligodendroglial cytoplasmic inclusions (GCIs) which gave pathological underpinning to SDS, SND and sOPCA being lumped together as one disease.

I think these two papers in 1989 served to consolidate the disparate clinical and pathological aspects of MSA into an entity that we should be able to recognise and diagnose, although we still do not understand why some patients are Parkinson-predominant and others cerebellar-predominant, or why the latter are more common than the former in Japan.

Despite current criteria, misdiagnosis of MSA as Lewy body disease or PSP, or viceversa, is still common, and the diagnosis is usually not made until half way through the disease. Better biomarkers will help earlier diagnosis, but even without them clinical diagnostic accuracy could be much better if clinicians keep a high index of suspicion in all cases of parkinsonism and sporadic cerebellar features and devote time to take a thorough history incorporating numerous available red flags, and to do a careful targeted examination.

Since 1989, research and papers on MSA have burgeoned. We, and others, increasingly together in multicentre studies of this orphan disease, have studied its epidemiology (prevalence 4-5/100 000), natural history ${ }^{13}$ and survival, developed clinical and quality of life rating scales, initiated the first clinical trials and applied new imaging techniques. In 1998, Maria Spillantini $^{14}$ showed that GCIs stained for alphasynuclein, but it seems to be a different 'prion-like' strain from the abnormal alphasynuclein in PD and DLB. The molecular pathogenesis of MSA has been explored in transgenic animals, but genetic studies in humans have been stubbornly negative. Nevertheless, the accumulation of scientific knowledge about MSA means that we now have the tools to conquer this dreadful disease, hopefully in the next two decades.

Funding The author has not declared a specific grant for this research from any funding agency in the public, commercial or not-for-profit sectors.

Competing interests None declared.

Patient consent for publication Not required.

Provenance and peer review Commissioned; internally peer reviewed.

(C) Author(s) (or their employer(s)) 2020. No commercial re-use. See rights and permissions. Published by BMJ.

\section{(D) Check for updates}

To cite Quinn N. J Neurol Neurosurg Psychiatry 2020;91:3-4.

Received 17 January 2019

Accepted 7 February 2019

J Neurol Neurosurg Psychiatry 2020;91:3-4. doi:10.1136/jnnp-2018-318187

\section{REFERENCES}

1 Graham JG, Oppenheimer DR. Orthostatic hypotension and nicotine sensitivity in a case of multiple system atrophy. J Neurol Neurosurg Psychiatry 1969;32:28-34.

2 Quinn N. Multiple system atrophy - the nature of the beast. J Neurol Neurosurg psychiatry. Special Supplement 1989:78-89.

3 Déjerine J. L'atrophie olivo-ponto-cérébelleuse. Nouv lconogr Salpêtr1900;13:330-70.

4 Bradbury S, Eggleston C. Postural hypotension. A report of three cases. Am Heart J;1:73-6.

5 Shy GM. A neurological syndrome associated with orthostatic hypotension. AMA Arch Neurol 1960:2:511-57.

6 Adams R, van Bogaert L, van der Eecken H, Bogaert Lvan, Eecken Hvander. Dégénérescences nigro-striées et cerebello-nigro-striées; PP. 219-232. Eur Neurol 1961;142:219-32.

7 Hoehn MM, Yahr MD. Parkinsonism: onset, progression and mortality. Neurology 1967;17:427.

8 Steele JC, Clifford Richardson J, Olszewski J. Progressive supranuclear palsy. Archives of Neurology 1964;10.

9 Rebeiz JJ, Kolodny EH, Richardson EP. Corticodentatonigral degeneration with neuronal achromasia. Arch Neurol 1968;18:20-33.

10 Bannister R, Oppenheimer DR, Roger B, R D. Degenerative diseases of the nervous system associated with autonomic failure. Brain 1972;95:457-74

11 Gilman S, Wenning GK, Low PA, et al. Second consensus statement on the diagnosis of multiple system atrophy. Neurology 2008;71:670-6.

12 Papp MI, Kahn JE, Lantos PL. Glial cytoplasmic inclusions in the CNS of patients with multiple system atrophy (striatonigral degeneration, olivopontocerebellar atrophy and Shy-Drager syndrome). J Neurol Sci 1989:94:79-100.

13 Wenning GK, Ben Shlomo Y, Magalhães M, et al. Clinical features and natural history of multiple system atrophy. An analysis of 100 cases. Brain 1994:117:835-45.

14 Spillantini MG, Crowther RA, Jakes $R$, et al. Filamentous alpha-synuclein inclusions link multiple system atrophy with Parkinson's disease and dementia with Lewy bodies. Neurosci Lett 1998;251:205-8. 